\title{
Advanced Hepatocellular Carcinoma in Adolescence Associated with Congenital Cholestasis: A Case Description
}

\author{
Morten Ladekarl ${ }^{\mathrm{a}} \quad$ Gerda Elisabeth Villadsen $^{\mathrm{b}} \quad$ Anne Roed Rudbeck $^{\mathrm{b}}$ \\ $\varnothing_{\text {ystein Aagenæs }}{ }^{\mathrm{e}}$ Jens Erik Nielsen ${ }^{c}$ Stephen Hamilton-Dutoit ${ }^{\mathrm{d}}$ \\ Marianne Nordsmark ${ }^{a}$ \\ Departments of ${ }^{\mathrm{a} O n c o l o g y,}{ }^{\mathrm{b}}$ Medicine V (Hepatology and Gastroenterology), 'Radiology \\ and ${ }^{d}$ Pathology, Aarhus University Hospital, Aarhus, Denmark; ${ }^{e}$ Department of Nutrition, \\ Institute of Basic Medical Sciences, Faculty of Medicine, University of Oslo, Oslo, Norway
}

\section{Key Words}

Hepatocellular carcinoma · Juvenile · Adolescence · Treatment · Chemotherapy · Congenital cholestasis syndrome

\begin{abstract}
This case describes the clinical course and treatment of a 17-year-old male patient with advanced hepatocellular carcinoma (HCC) arising in a non-cirrhotic liver. The disease was thought to be caused by a congenital cholestatic syndrome associated with intermittent oedema in childhood, resembling the rare Aagenaes syndrome. Treatment choices in advanced $\mathrm{HCC}$ arising in adolescence are discussed.
\end{abstract}

\section{Introduction}

Hepatocellular carcinoma (HCC) is a rare tumour in young adults. In older patients, common predisposing conditions include cirrhosis in general, and in particular chronic liver disease associated with persistent hepatitis $\mathrm{B}$ and $\mathrm{C}$ infection. However, young patients who develop HCC are less likely to have associated chronic liver disease (33\%) compared to adults (70-90\%) [1]. In children, inborn errors of metabolism, such as alpha-1-antitrypsin deficiency, hereditary tyrosinaemia, Gaucher's disease, congenital biliary atresia, urea cycle defects, and familial cholestatic syndrome caused by a bile salt export pump deficiency, may 
be the underlying cause [2]. Prognosis in the presence of metastatic disease is poor, although it may be somewhat better in children and younger adults compared to older adults, with long-term survival of 10-20\% compared to less than 5\%, respectively [1].

We describe a case of advanced HCC in a young patient arising in a non-cirrhotic liver, which was thought to be causally associated with a congenital cholestasis syndrome.

\section{Case}

The patient was first admitted to the hospital as an infant when he was 2 weeks old. The reason was weakness and jaundice. Bilirubin was elevated to $500 \mu \mathrm{mol} / \mathrm{l}$, of which only one third was conjugated. A diagnosis of $\mathrm{ABO}$ haemolytic disease of the newborn was suspected, but intensive phototherapy and exchange transfusion had only limited effect. A liver biopsy performed at the age of 2 months showed severe pan- and multiacinar canalicular cholestasis with numerous bile thrombi and cholestatic rosettes. Liver cells were swollen with marked feathery degeneration and there was widespread giant cell transformation. There were scattered apoptotic hepatocytes but only minimal accompanying inflammation. In addition, there was focal extramedullary haematopoiesis. Liver architecture was intact without evidence of fibrosis. Portal bile ducts were present in normal numbers, and there was no morphological evidence of extrahepatic large duct obstruction. A biliary scintigraphy confirmed cholestasis, showing no drainage of bile into the central hepatic bile ducts or the duodenum, and the extrahepatic bile ducts were normal at endoscopy. Bilirubin slowly normalised during the following year, while alkaline phosphatases stayed elevated at 1,000$1,500 \mathrm{U} / \mathrm{l}$ for several years, indicating a mild, long-term cholestasis (fig. 1). In early childhood, the patient developed recurrent, intermittent swollen legs and periorbital oedema, and had episodes of stomach pain and fatigue. Repeated liver biopsies at the age of 3 and 6 years showed only minimal, non-specific portal inflammation without evidence of cholestasis or fibrosis. A diagnosis of Aagenaes syndrome was suspected; however, no typical genetic alterations were found, and the patients' condition improved spontaneously and alkaline phosphatases normalised as he reached adolescence.

At the age of 17 years, the patient was admitted to the hospital with severe abdominal pain and vomiting. A CT scan demonstrated a $150 \times 100 \mathrm{~mm}$ necrotic tumour in the right liver lobe with multiple hepatic satellite nodules, multiple metastases to the lungs, a tumour embolus in the right atrium and extensive thromboses involving the inferior vena cava, hepatic vein and portal vein. Serum $\alpha$-foetoprotein $(\alpha F P)$ was markedly raised at 296,000 $\mathrm{U} / \mathrm{ml}$ (normal $<14 \mathrm{U} / \mathrm{ml}$ ), while hCG was normal. No clinical or biochemical evidence of cirrhosis was found and hepatitis virus titres were negative. A biopsy from the large liver mass showed a malignant tumour composed of hepatocyte-like cells, organised in a trabecular pattern. There was focal clear-cell morphology and no evidence of fibrolammellar carcinoma. Immunohistochemical staining revealed a typical phenotype, including tumour cell positivity for Hep-Par1, glypican-3 and $\alpha \mathrm{FP}$. A diagnosis was made of moderately welldifferentiated HCC. A needle biopsy taken at the same time from a lung metastasis revealed infiltrating HCC, subsequently confirmed by immunohistochemistry. A biopsy from the nontumorous liver showed reactive tissue without evidence of cirrhosis.

The patient's oncological treatment is summarised in figure 2 together with $\alpha \mathrm{FP}$ values and the results of tumour evaluation by CT-scans. At the time of first treatment his poor condition (WHO Performance Status (PS) 3) precluded combination chemotherapy and single-drug cisplatin was therefore offered. Toxicity comprised of vomiting, mild tinnitus and neutropenia (CTC grade I). In addition, there was a rise in liver enzymes (grade II). Prior 
to the second treatment cycle, his condition had improved (PS 2), allowing the administration of five series of combination chemotherapy, which contained gemcitabine, docetaxel and cisplatin. Supportive pegfilgrastim $4 \mathrm{mg}$ s.c. was given on day 2 of each cycle. Toxicity included diarrhoea and neutropenia CTC grade I, together with vomiting, anorexia, anaemia and alopecia (grade II). A further improvement in the patient's clinical condition was observed during this treatment, and its effect was confirmed by a major, partial response on the corresponding CT scans (fig. 3). The response defined by CT was preceded by a rapidly dropping $\alpha \mathrm{FP}$. After a pause in chemotherapy, CT scans showed progression, accompanied by a continuous rise in $\alpha \mathrm{FP}$. At the first progression, sorafenib at standard dose was offered. Toxicity was dose limiting and consisted of neutropenia grade II, diarrhoea, vomiting, rash and pruritus grade III, requiring a 4-week treatment break. Sorafenib was then administered at a reduced dose for 2 weeks and later escalated with acceptable toxicity. At the 2nd objective progression the patient was offered chemotherapy with gemcitabine and oxaliplatin, but no apparent effect was observed. Toxicity consisted of paraesthesia grade I and neutropenia grade II. Up to this point, the patient had remained in excellent general condition (PS 0-1). At the 3rd progression, experimental treatment with erlotinib plus bevacizumab was intended. However, bevacizumab was never administered because of deterioration in the patient's general condition. He continued on best supportive care and lived for a further 3 months, totalling 13 months of survival after initiation of chemotherapy.

\section{Discussion}

In this rare case, the development of HCC was associated with a history of neonatal and childhood cholestasis with elevated bilirubin and alcalic phosphatases, and intermittent episodes of periorbital oedema and oedema in the legs, stomach pain and fatigue. These symptoms resemble those of the rare Aagenaes syndrome, also called lymphoedema cholestasis syndrome [3]. The heritance of this disorder is mainly autosomal recessive; however, dominant inheritance has also been proposed. The gene involved is located on chromosome 15q [4]. A key symptom is transient jaundice with increased conjugated bilirubin that becomes evident soon after birth with recurrent episodes throughout life. Oedema in the legs due to hypoplasia of the lymphatic vessels begins around school age and may progress. Globally, more than 80 cases have been described. There has been only one previous case diagnosed in Denmark, apart from the current case, in which the diagnosis was strongly suspected. Patients with Aagenaes syndrome have an approximately $25 \%$ risk of developing liver cirrhosis, mainly in early childhood [5]. One previous patient who had frequent episodes of cholestasis died at the age of 50 years with cirrhosis and HCC (Professor Aagenæs, personal communication 2012). In the current case, the diagnosis of Aagenaes syndrome could not be clearly established, in part because of the lack of permanent signs of lymphoedema and absence of typical genetic alterations. Although not specific, the histological picture was consistent with various forms of congenital neonatal cholestasis syndrome, including Aagenaes syndrome.

The choice of systemic treatment in juvenile HCC is difficult, since no phase III studies of adolescent patients with advanced HCC have been performed. Therefore, there is no clear evidence that treatment prolongs life [6]. An aggressive approach, including liver tumour resection or liver transplantation and metastasectomy when feasible, is often advocated. In contrast to adult patients with HCC, in whom the tyrosine-kinase inhibitor sorafenib is the only approved drug today, pediatric and juvenile patients are often treated with chemotherapy with much higher response rates. For example, cisplatin and doxorubicin or cisplatin/5- 
fluorouracil/vincristine produced responses in approximately 50\% of treated patients [1]. Molecular differences in tumorigenesis and in the underlying liver diseases may account for this difference in effect, comparing children and adults [6]. Interpretation of treatment reports is, however, hampered since children with hepatoblastoma, a tumour type which is more chemosensitive than HCC [6], were included.

Chemotherapy for adult HCC must be regarded as experimental. Early studies, e.g. with doxorubicin, showed only modest response rates with significant toxicity, without any clear survival benefits [7]. More recently, phase II-studies of newer drugs showed response rates around $20 \%$ with acceptable toxicity, for example when using gemcitabine/oxaliplatin, in one study combined with the anti-angiogenetic antibody bevacizumab [8]. An Asian study of 371 patients randomised to either oxaliplatin +5 -fluorouracil/leucovorin or doxorubicin was insignificant at the preplanned final survival analysis $(p=0.0695)$, but significant at a follow-up analysis $(p=0.0425)$ [9]. A randomised phase II study of 96 patients treated by either sorafenib/doxorubicin or doxorubicin showed a clear advantage for the two-drug combination (median time to progression 6.4 vs. 2.8 months, $p=0.02$ ) and also the median overall survival was significantly improved (13.7 vs. 6.5 months, $p=0.006$ ) [10]. Results of a phase III-study of this combination are pending. Response to chemotherapy is apparently more frequently seen in patients with HCC in nonalcoholic cirrhosis, in the absence of cirrhosis, or in patients with rare variants of HCC, and complete responders have even been reported in patients with metastatic disease [11]. These types of patients would therefore be the best candidates for experimental chemotherapy.

The effect of sorafenib has only been studied in adult patients, most of whom had HCC associated with cirrhosis, or with hepatitis B or C virus infection. Sorafenib is a per oral tyrosine kinase inhibitor with activity against multiple growth factors, especially angiogenic growth factors [12]. Two randomised phase III-studies showed modest median survival benefits of 2.8 and 2.3 months, respectively, the hazard ratio of sorafenib versus placebo being approximately $0.69[12,13]$. Objective response rates reported were less than $5 \%$, but rare major responders have been documented even in the setting of metastatic HCC [14]. The effect of sorafenib in children and young patients is unknown, although a recent phase I study showed that the treatment is feasible [15].

The current case illustrates that early development of HCC may be associated with congenital cholestasis, even in the absence of cirrhosis. It confirms that chemotherapy, although experimental, is feasible and tolerable in juvenile advanced HCC arising in a noncirrhotic liver and can provide a major objective response and a meaningful palliation for individual patients.

\section{Disclosure Statement}

The authors declare no conflict of interest.

\section{References}

1 Czauderna P, Mackinlay G, Perilongo G, Brown J, Shafford E, Aronson D, Pritchard J, Chapchap P, Keeling J, Plaschkes J, Otte JB; Liver Tumors Study Group of the International Society of Pediatric Oncology: Hepatocellular carcinoma in children: results of the first prospective study of the International Society of Pediatric Oncology group. J Clin Oncol 2002;20:2798-2804.

2 Cruz O, Laguna A, Vancells M, Krauel L, Medina M, Mora J: Fibrolamellar hepatocellular carcinoma in an infant and literature review. J Ped Hematol Oncol 2008;30:968-971. 


\section{Case Reports in Oncology}

\begin{tabular}{l|l}
\hline Case Rep Oncol 2013;6:98-103 \\
\hline DOI: $\underline{10.1159 / 000348715}$ & $\begin{array}{l}\text { C 2013 S. Karger AG, Basel } \\
\text { www.karger.com/cro }\end{array}$ \\
\hline
\end{tabular}

Ladekarl et al.: Advanced Hepatocellular Carcinoma in Adolescence Associated with Congenital Cholestasis: A Case Description

-3 Aagenaes 0, Van der Hagen C-B, Refsum S: Hereditary recurrent intrahepatic cholestasis from birth. Arch Dis Childhood 1968;43:646-657.

4 Bull LN, Roche E, Song EJ, Pedersen J, Knisely AS, van Der Hagen CB, Eiklid K, Aagenaes O, Freimer NB: Mapping of the locus for cholestasis-lymphedema syndrome (Aagenaes syndrome) to a 6.6-cM interval on chromosome 15q. Am J Hum Gen 2000;67:994-999.

$\$ 5$ Drivdal M, Trydal T, Hagve TA, Bergstad I, Aagenaes O: Prognosis, with evaluation of general biochemistry, of liver disease in lymphoedema cholestasis syndrome 1 (LCS1/Aagenaes syndrome). Scand J Gastroenterol 2006;41:465-471.

6 Gupta AA, Gerstle JT, Ng V, Wong A, Fecteau A, Malogolowkin MA, Meyers RL, Grant D, Grant RM: Critical review of controversial issues in the management of advanced pediatric liver tumors. Ped Blood Cancer 2011;56:1013-1018.

7 Thomas MB: Systemic therapy for hepatocellular carcinoma. Cancer J 2008;14:123-127.

-8 Zhu AX, Blaszkowsky LS, Ryan DP, Clark JW, Muzikansky A, Horgan K, Sheehan S, Hale KE, Enzinger PE, Bhargave P, Stuart S: Phase II study of gemcitabine and oxaliplatin in combination with bevacizumab in patients with advanced hepatocellular carcinoma. J Clin Oncol 2006;24:1898-1903.

9 Qin SK, Thongprasert S, Lim HY, Liang L, Zhang Y, Rau M-M, Yang T-S, Seetalakom K, Kim JH, Zhou Y: Oxaliplatin + 5-fluorouracil/leucovorin (FOLFOX4) in advanced HCC: updated efficacy results of the EACH trial. ESMO 2010; Abstract no. 3435.

10 Abou-Alfa GK, Johnson P, Knox JJ, Capanu M, Davidenko I, Lacava J, Leung T, Gansukh B, Saltz LB: Doxorubicin plus sorafenib versus doxorubicin alone in patients with advanced hepatocellular carcinoma: a randomized trial. JAMA 2010;304:2154-2160.

11 Boschetti G, Walter T, Hervieu V, Cassier P, Lombard-Bohas C, Adham M, Scoazec JY, Dumortier J: Complete response of hepatocellular carcinoma with systemic combination chemotherapy: not to get out the chemotherapy? Eur J Gastroenterol Hepatol 2010;22:1015-1018.

12 Llovet JM, Ricci S, Mazzaferro V, Hilgard P, Gane E, Blanc JF, de Oliveira AC, Santoro A, Raoul JL, Forner A Schwartz M, Porta C, Zeuzem S, Bolondi L, Greten TF, Galle PR, Seitz JF, Borbath I, Häussinger D, Giannaris T, Shan M, Moscovici M, Voliotis D, Bruix J; SHARP Investigators Study Group: Sorafenib in advanced hepatocellular carcinoma. New Engl J Med 2008;359:378-390.

13 Cheng AL, Kang YK, Chen Z, Tsao CJ, Qin S, Kim JS, Luo R, Feng J, Ye S, Yang TS, Xu J, Sun Y, Liang H, Liu J, Wang J, Tak WY, Pan H, Burock K, Zou J, Voliotis D, Guan Z: Efficacy and safety of sorafenib in patients in the Asia-Pacific region with advanced hepatocellular carcinoma: a phase III randomised, double-blind, placebocontrolled trial. Lancet Oncol 2008;10:25-34.

14 Inuzuka T, Nishikawa H, Sekikawa A, Takeda H, Henmi, Sakamoto A, Saito S, Kita R, Kimura T, Osaki Y, Kudo M: Complete response of advanced hepatocellular carcinoma with multiple lung metastases treated with sorafenib: a case report. Oncology 2011;81(suppl 1):152-157.

15 Widemann BC, Kim A, Fox E, Baruchel S, Adamson PC, Ingle AM, Bender JG, Burke M, Weigel B, Stempak D, Balis FM, Blaney SM: A phase I trial and pharmacokinetic study of sorafenib in children with refractory solid tumors or leukemias: a Children's Oncology Group Phase I Consortium report. Clin Cancer Res 2012;18:6011-6022.

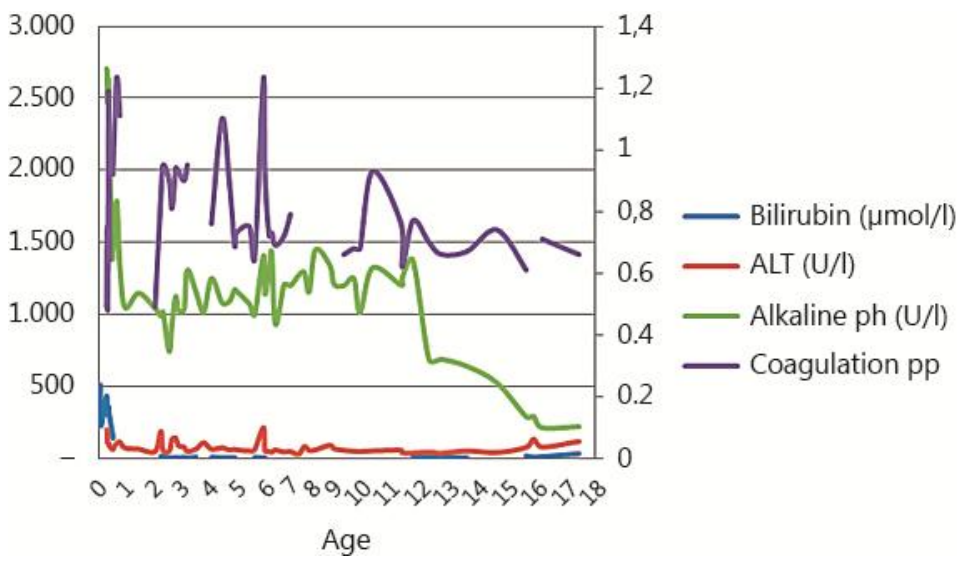

Fig. 1. Liver function blood tests according to the patient's age. Bilirubin, ALT (alanine aminotransferase) and Alkaline ph (alkaline phosphatase) with units shown on left axis. Coagulation pp (prothrombin time) with units shown on right axis. 


\section{Case Reports in Oncology}

\begin{tabular}{l|l}
\hline Case Rep Oncol 2013;6:98-103 \\
\hline DOI: $\underline{10.1159 / 000348715}$ & $\begin{array}{l}\text { C 2013 S. Karger AG, Basel } \\
\text { www.karger.com/cro }\end{array}$ \\
\hline
\end{tabular}

Ladekarl et al.: Advanced Hepatocellular Carcinoma in Adolescence Associated with Congenital Cholestasis: A Case Description

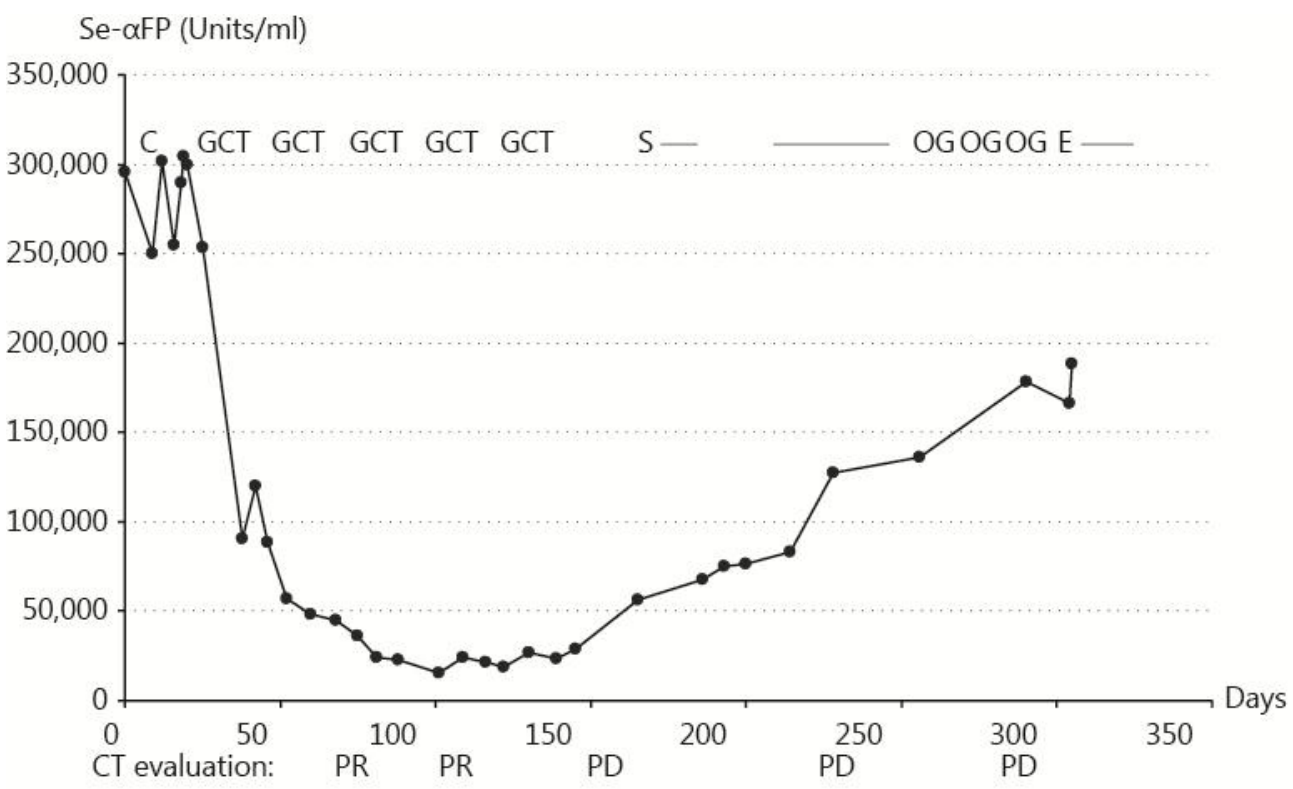

Fig. 2. Serum $\alpha$-foetoprotein $(\alpha \mathrm{FP})$ measured during treatment. Treatment schedules indicated: $\mathrm{C}=$ cisplatin $100 \mathrm{mg} / \mathrm{m}^{2}$ in a 3-week cycle; GCT = gemcitabine (G) 1,000 mg/m² day 1 and 8, cisplatin (C) 70 $\mathrm{mg} / \mathrm{m}^{2}$ day 1 , and docetaxel $\left(\right.$ Taxol $\left.^{\circledR}, \mathrm{T}\right) 175 \mathrm{mg} / \mathrm{m}^{2}$ day 1 in a 3-week cycle; $\mathrm{S}=$ sorafenib $400 \mathrm{mg}$ p.o. b.i.d. reduced to $200 \mathrm{mg}$ daily for 2 weeks after a 4-week break and then escalated to $400 \mathrm{mg}$ daily; $\mathrm{OG}=$ oxaliplatin (O) $85 \mathrm{mg} / \mathrm{m}^{2}$, and gemcitabine $(\mathrm{G})$ 1,000 mg/m² every 2nd week; E = erlotinib p.o. $100 \mathrm{mg}$ daily. Indicated below the $\mathrm{x}$-axis are the results of tumour measurements by RECIST ver. 1.1. PR = Partial response; $\mathrm{PD}=$ progressive disease.

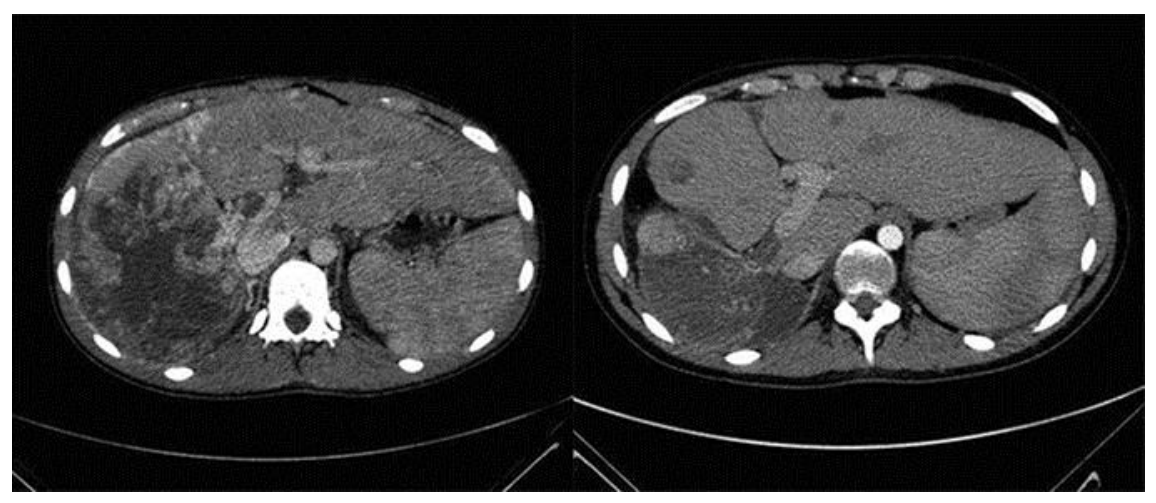

Fig. 3. CT scans at baseline (left) and after six series of chemotherapy (right), showing a major partial response with shrinkage of the primary liver tumour. 